\title{
Aspirin inhibits proliferation and metastasis of canine mammary gland tumor cells through Wnt signaling axis
}

\author{
Enshuang Xu, Mengxin Hu, Yun Liu \\ Department of Veterinary Surgery, College of Veterinary Medicine, Northeast Agricultural University, Key Laboratory of Comparative Medicine, \\ Harbin, China \\ Contributions: (I) Conception and design: E Xu; (II) Administrative support: E Xu; (III) Provision of study materials or patients: E Xu; (IV) Collection \\ and assembly of data: $\mathrm{E} \mathrm{Xu,} \mathrm{M} \mathrm{Hu;} \mathrm{(V)} \mathrm{Data} \mathrm{analysis} \mathrm{and} \mathrm{interpretation:} \mathrm{E} \mathrm{Xu;} \mathrm{(VI)} \mathrm{Manuscript} \mathrm{writing:} \mathrm{All} \mathrm{authors;} \mathrm{(VII)} \mathrm{Final} \mathrm{approval} \mathrm{of}$ \\ manuscript: All authors. \\ \#These authors contributed equally to this work. \\ Correspondence to: Yun Liu. Department of Veterinary Surgery, College of Veterinary Medicine, Northeast Agricultural University, Key Laboratory of \\ Comparative Medicine, Harbin 150030, China. Email: abliuyun@yeah.net.
}

Background: Breast cancer is one of the most common, lethal types of neoplasia. The high mortality is largely due to rapid growth and distal metastasis. Epithelial-mesenchymal transition (EMT) and increased activity of matrix metalloproteinases (MMPs), which are related to tumor aggressiveness and progression, are known to be essential processes. Aspirin, a classic anti-inflammatory treatment, has been shown to inhibit the different types of cancer, though its research have yet to be elucidated and remain controversial.

Methods: We set out to elucidate the mechanism of Aspirin against the metastasis of canine mammary gland tumor cells (CMGTs), and provide theoretical support for the rational use of non-steroidal antiinflammatory drugs. Firstly, we utilized CCK8, wound healing and transwell invasion assays to determine the effect of Aspirin on proliferation and migration of CMGTs. Next, we determined the effect of Aspirin on $\mathrm{Wnt} / \beta$-catenin signaling by cellular immunofluorescence and western blot analysis. Finally, Wnt/ $\beta$-catenin pathway activating agent (Wnt3a) and inhibitor (FH535) were utilized to further validate the relationship between Aspirin and Wnt/ $\beta$-catenin signaling.

Results: The results indicated that Aspirin inhibits proliferation and migration of CMGTs in a time-and concentration-dependent manner. Moreover, the inhibitory effect of Aspirin on CMGTs was reduced upon addition of a Wnt pathway activating agent (Wnt3a), while the effect following the addition of Wnt pathway inhibitor (FH535) remained the same as that of Aspirin.

Conclusions: Our study demonstrates that Aspirin can inhibit the proliferation, migration and invasion by inhibiting $\mathrm{Wnt} / \beta$-catenin signaling, which suggest it can be a promising tool for deterring metastasis of CMGTs.

Keywords: Aspirin; canine mammary gland tumor; Wnt3a; Wnt//-catenin signaling

Submitted Oct 29, 2020. Accepted for publication Jan 06, 2020.

doi: $10.21037 /$ tcr-20-3172

View this article at: http://dx.doi.org/10.21037/tcr-20-3172

\section{Introduction}

Breast cancer is the most common and lethal types of neoplasia. A majority of breast cancer recurrences and high mortality are largely due to distant metastasis particularly to the lungs and the brain (1). Tumor metastasis can cause failure of conventional treatment, and the 5-year survival of patients with advanced breast cancer remains only $20 \%$. At present, there is no good options for metastatic breast cancer. Treatment involves increasing the use of chemotherapeutic drugs, which can cause irreversible damage to the body. Therefore, identification of promising 
therapeutic agents or novel approaches that arrest the invasive and metastatic behaviors of cancer cells is urgently needed.

Epithelial-mesenchymal transition (EMT) and matrix metalloproteinases (MMPs), both of which are related to tumor aggressiveness and progression, are known to be essential processes $(2,3)$. EMT can cause epithelial cells to lose intercellular adhesion and attain the characteristics of interstitial cells, thereby enhancing the migration and invasive ability of cells. Cell adhesion plays a significant role in tumor invasion and metastasis, and a decrease in cell adhesion is one of the necessary conditions for metastasis. Intercellular adhesion molecules change the adhesion characteristics of tumor cells, making them separate from the primary lesion and adhere to the extracellular matrix. Cadherin is a calcium-dependent glycoprotein that is responsible for calcium-dependent intercellular adhesion. E-cadherin is an important member of the cadherin family. Yoshida $\mathrm{K}$ found that $\mathrm{E}$-cadherin expression is lost in malignant CMGTs, and its expression is correlated to survival (4). MMPs are derived primarily from stromal cells within the microenvironment, including neutrophils, macrophages, dendritic cells, lymphocytes, endothelial cells, fibroblasts, and hematopoietic stem cells. MMPs are closely related to the development of breast cancer invasion and metastasis, inflammatory response and angiogenesis. As important members of the MMPs family, MMP-2 and MMP-9 have been proven to be capable of pro-inflammatory factors in order to induce cytoskeletal rearrangement, weaken intercellular adhesion, and promote the invasion and metastasis of breast cancer. MMP-2 and MMP-9 are major enzymes involved in degradation of the extracellular matrix and basement membrane $(3,5,6)$.

Aspirin, also known as acetylsalicylic acid, is a nonsteroidal anti-inflammatory drug (NSAID). Aspirin is widely utilized in various clinical fields, including as an antipyretic, analgesic, anti-rheumatism, as well as for prevention and treatment of cardiovascular and cerebrovascular diseases (7). In recent years, a number of clinical epidemiological studies have indicated that aspirin intake is associated with prevention and death from many types of cancer. Sandler et al. analyzed 635 patients with early-stage colorectal cancer who were given either 325 $\mathrm{mg}$ of aspirin a day or a placebo (8). The results from this study indicated that patients that took aspirin were at a significantly lower risk of developing adenomas compared to those taking placebo. With increasing number of studies, aspirin does not only show antitumor effects in colorectal cancer (9), but also in other cancer. Rosenberg $\mathrm{K}$ found that aspirin can reduce the risk of ovarian cancer (10). In addition, Aspirin in a combination with the cisplatin inhibit the migration of non-small cell lung carcinoma stem-like cells by targeting mTOR-Akt axis (11). And Khan FU using cell lines, animal model and database analysis shows that Aspirin inhibits breast cancer cell migration and invasion by attenuating $W n t / \beta$-catenin signaling and suppressing fibromodulin expression (12). On the other hand, in osteosarcoma cell lines Aspirin reduced cell viability in a dose- and time-dependent manner (13). However, the use of aspirin has been controversial in patients with breast cancer. Li et al. study of 1,024 patients found no association between aspirin use and survival among breast cancer patients (14). Therefore, the role of Aspirin in breast cancer needs to be further verified. Knapp et al. proposed that NSAIDs do not rely on cytotoxic effects on canine mammary gland tumor cells (CMGTs), but there are other mechanisms (15). On the contrary, Saito T demonstrated that aspirin as an effective COX-2 inhibitor can effectively inhibit the growth of CMGTs (16). However, the effect of Aspirin against cancer metastasis has not yet been fully explored in aggressive breast cancer and the exact molecular mechanisms responsible for this effect have not been elucidated.

Wnt pathway have a key role in the growth and development of the body, steady-state maintenance and tumorigenesis (17). The Wnt pathway can be separated into a canonical and a non-canonical Wnt signaling. In this case, canonical Wnt signaling (Wnt/ $\beta$-catenin) is mainly composed of the secreted signaling protein $\mathrm{Wnt}$, a transmembrane receptor protein (Frizzled) and a plurality of plasmin proteins (GSK3 $\beta, \beta$-catenin) in cells. Wnt/ $\beta$-catenin signaling refers to the signaling pathway in which the extracellular secretory glycoprotein Wnt binds to trans membrane receptor protein Frizzled, which activates the intracellular protein Disheveled (Dsh) and inhibits the activity of serine/threonine kinase GSK3 $\beta$. $\beta$-catenin, which is in dephosphorylated using APC and Axin, can escape degradation of the ubiquitin hydrolysis system and accumulate with in the cytoplasm, enter the nucleus and interact with the transcriptional regulator LEF/TCF in order to activate the transcription of target genes. As a key molecule of Wnt signaling, the protein expression of $\beta$-catenin is related to the opening or closing of the Wnt/ $\beta$-catenin signaling. In malignant tumor cells, including colon cancer, breast cancer, liver cancer, and lung cancer, $\beta$-catenin accumulates within cytoplasm and nucleus, 
leading to abnormal activation of its downstream target genes, such as c-myc, cyclin D1, and PPAR- $\delta$ (18). Many researchers determined that the anti-tumor effect of Aspirin is related to $\mathrm{Wnt} / \beta$-catenin signaling $(12,19-22)$. However, these studies have mainly focused on aspirin inhibiting tumor proliferation and promoting apoptosis, and less on tumor metastasis and its exact molecular mechanism has not yet been clarified.

In recent years, many important research have been made in oncology research, a large proportion of which are related to the application of more ideal experimental models in research. Canine mammary gland tumors (CMGT) is similar to that of human breast tumor, and CMGT almost has similar complexity of human breast cancer in vivo, such as influencing of immune function, changing of the tumor microenvironment and remodeling of stroma. The study and exploration of the mechanism of occurrence and metastasis of CMGT, as well as therapeutic effect of related drugs, can provide relevant reference data and enlightenment significance for breast cancer. Hence, we demonstrated the effect of Aspirin on proliferation and migration of CMGTs, which are consistent with results from our previous studies (23). Secondly, we analyzed the role of $W n t / \beta$-catenin signaling in the inhibition of CMGTs metastasis, and explored the pharmacological mechanisms. These results demonstrate, for the first time, that Aspirin holds the potential for inhibiting cancer metastasis in CMGTs, and that its suppression is mediated by Wnt signaling pathways, regulation of MMPs and EMT. This study provides theoretical support for the anti-tumor effect of Aspirin, and is of great for the discovery of new efficacy and reduction of chemotherapy drug use. We present the following article in accordance with the MDAR checklist (available at http://dx.doi.org/10.21037/tcr-20-3172).

\section{Methods}

\section{Reagents and CMGT lines culture}

Aspirin, Wnt3a protein $(0.1 \mathrm{ug} / \mathrm{mL})$, FH535 (10 uM) purchased from Sigma-Aldrich (St. Louis, MO, USA) was dissolved in dimethyl sulfoxide (Sigma) and kept at $-20{ }^{\circ} \mathrm{C}$ for studies. Prior to use, the stock aspirin solution was further diluted with serum-free DMEM (Thermo Fisher Scientific, Waltham, USA).

The CMGT lines (CHMp and CHMm), which were extracted from the primary mass of an inflammatory mammary gland tumor of a 12 -year-old female dog and characterized in the Department of Veterinary Medical Sciences, University of Tokyo, Japan, were used in this study (24). CHMp is derived from the primary lesion, and CHMm is derived from post-metastatic pleural effusion. The CHMp and CHMm cells were nurtured in DMEM medium supplemented with $10 \%$ fetal bovine serum, $100 \mathrm{mg} / \mathrm{mL}$ streptomycin (Sigma), $100 \mathrm{U} / \mathrm{mL}$ penicillin (Sigma), $0.1 \%$ fungizone (Sigma) and $1 \%$ glutamine (Sigma), incubated at $37{ }^{\circ} \mathrm{C}$ in a humidified $5 \% \mathrm{CO}_{2}$ atmosphere.

\section{Assay cell viability of CMGTs}

The proliferative capacities of CMGTs were assessed using the Cell Counting Kit-8 (Sigma), as described previously (23). Briefly, CHMp and CHMm cells were cultivated and seeded onto 96-well plates at a density of 2000 cells per well. According to experiment design, cells were divided into different concentration groups (Aspirin 1.25, 2.5, $5,7.5,10,12.5$ and $15 \mathrm{mM}$ ) for $12,24,36$ and $48 \mathrm{~h}$ at $37^{\circ} \mathrm{C}$. Then, the treated cells were incubated with a $10 \mu \mathrm{L}$ Cell Counting Kit-8 solution for $1 \mathrm{~h}$. Absorbency was measured using a microplate reader (BioTek, Vinooski, VT, USA) at $450 \mathrm{~nm}$. Each experiment was repeated at least six times.

\section{Wound bealing assay}

CHMp and CHMm cells were cultured in a 6-well plate (Corning, New York, USA), according to culture conditions that were described previously (25). However, the medium didn't contain serum. Cells were assigned to several groups when adherent cells were multiplied to $80-90 \%$ of per well bottom surface area. A straight line was drawn on the bottom of the well using a $100 \mu \mathrm{L}$ pipette tip and cells were then treated with different concentrations of Aspirin for 12 and $24 \mathrm{~h}$. Wound closure photographs were captured using a microscope (Nikon, Kyoto, Japan). The wound area was measured at least three times by using Image $\mathrm{J}$ software. Later, scratches were photographed at low power $(\times 100)$. The results were expressed as percent wound closure compared to the controls (26).

\section{Transwell invasion assay}

CHMp and CHMm cells were cultured with in serumfree medium containing aspirin, Wnt3a or FH535 for 36 h. First, Matrigel and cells were diluted with serum-free DMEM medium. Twenty-four-well plate is added $50 \mu \mathrm{L}$ 
diluted matrigel to per upper chamber and incubated for 30 minutes at $37^{\circ} \mathrm{C}$, and $5 \times 10^{4} / \mathrm{mL}$ cells suspension were added to per upper chamber at $200 \mu \mathrm{L} .20 \%$ FBS medium of 500 $\mu \mathrm{L}$ was added to the lower chamber. Second, chambers were rinsed with phosphate buffered saline, soaked in paraformaldehyde for 30 minutes and dried and added 500 $\mu \mathrm{L} 0.1 \%$ crystal violet straining solution staining $(27,28)$. Finally, the pictures counted the number of cells were captured at least three under inverted microscope $(\times 200)$ by Nikon Corporation (Kyoto, Japan) with computer.

\section{Experiments with immunofluorescence staining for Aspirin-treated CHMp and CHMm cells}

The cells were collected in the logarithmic growth phase, seeded in a $35 \mathrm{~mm}$ culture dish with $1 \times 10^{5}$ cells/well, and grown in a cell incubator. After $15 \mathrm{~h}$ of cell culture, the medium was replaced with a drug medium containing $5 \mathrm{mM}$ of aspirin. Next, $2 \mathrm{~mL}$ of $4 \%$ paraformaldehyde was added to the cells at room temperature for 30 minutes after culturing in a drug medium for $36 \mathrm{~h}$. The $4 \%$ paraformaldehyde was then discarded and the cells were washed with PBS. Then, $0.1 \%$ Triton-X100 $1 \mathrm{~mL}$ at room temperature was added to these cells for 15 minutes, and incubated with antibodies ( $\beta$-catenin, p-GSK3 $\beta$ from Bioss, Beijing, China) for $12 \mathrm{~h}$ at $4{ }^{\circ} \mathrm{C}$. Secondary antibodies (Wanlei, Shenyang, China) were incubated at room temperature in the dark for 30 minutes, and were kept away from light. Finally, DAPI was stained for 15 minutes and protected from light at room temperature. The laser confocal microscope (Nikon) was utilized to observe the staining results.

\section{Western blot}

Dilutions of each antibody were used for western blot, according to instructions. Overall, $30 \mu \mathrm{g}$ total protein of CHMp and CHMm cells treated with aspirin, Wnt3a protein or FH535 for $36 \mathrm{~h}$ was added to each well of a SDS-PAGE gel, respectively. After electrophoresis, the desired protein transferred onto nylon membranes. The membranes were then incubated for $2 \mathrm{~h}$ at room temperature with TBST buffer containing $5 \%$ non-fat milk. Next, membranes were rinsed in TBST and incubated with primary antibodies in primary antibody diluent overnight at $4{ }^{\circ} \mathrm{C}$, as well as secondary antibodies (Wanlei) for $2 \mathrm{~h}$ at room temperature with slight shaking. Finally, Li-Cor Odyssey infrared image scanning system was utilized to observe changes in protein bands and protein expression. Primary antibodies included: mouse anti-MMP2, rabbit anti-MMP9, mouse anti-VEGF, and mouse anti-Wnt3 (Bioss). Additionally, we utilized mouse anti-PPAR, mouse anti-c-myc, rabbit anti-cyclinD1, mouse anti-E-cadherin, mouse anti- $\beta$-tubulin, rabbit anti-GSK3 $\beta$, mouse anti-pGSK3 $\beta$, mouse anti-p- $\beta$-catenin, and mouse anti- $\beta$-catenin (Wanlei).

\section{Statistical analysis}

The data is presented as the mean \pm SD. Statistical comparisons between treated and control groups were calculated by Student's $t$-tests using GraphPad Prism 5, and multiple groups were determined by two-way ANOVA test $(n \geq 3)$. A value of $\mathrm{P}<0.05$ was considered to be significant; $\mathrm{P}<0.01$ and $\mathrm{P}<0.001$ was considered to be strongly significant.

\section{Results}

\section{Effect of aspirin on cell activity and metastasis for CMGTs}

We evaluated the effect of different concentrations of Aspirin on the proliferation of the primary tumor cell line CHMp and the metastatic tumor cell line CHMm using CCK8 assay. We found that Aspirin induced a significant dose- and time-dependent inhibition of cellular proliferation in CMGTs (Figure 1A), beginning with concentrations of $2.5 \mathrm{mM}$ at 12,24 and $36 \mathrm{~h}$, and $1 \mathrm{mM}$ at $48 \mathrm{~h}$, respectively.

Next, we conducted wound healing and transwell invasion assays were used to detect the effect of Aspirin on migration and invasion of CMGTs. The results showed that compared to the control group, the wound healing area (Figure $1 B, C$ ) and number of invading cells (Figure 1D,E) decreased. Aspirin at concentrations $\geq 5 \mathrm{mM}$ significantly inhibited the migration and invasion of CMGTs at $24 \mathrm{~h}$ compared to the control group. It has been suggested that Aspirin can inhibit migration and invasion of CMGTs in a time-and concentration-dependent manner. The concentrations used were lower compared to those of IC50, indicating that Aspirin still inhibits migration and invasion of CMGTs under sub-toxicity.

\section{Aspirin inbibits canonical Wnt/ß-catenin signaling in CMGTs}

As mentioned prior, Wnt signaling pathway plays a key 

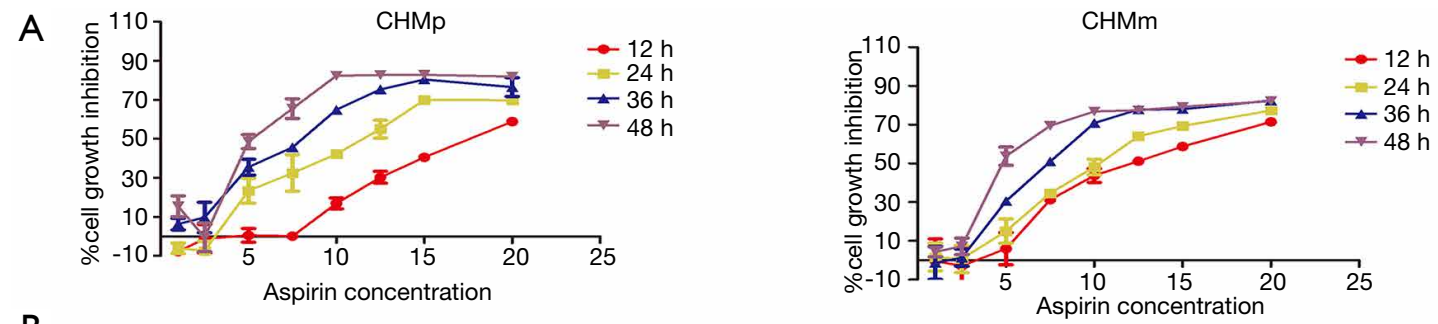

B

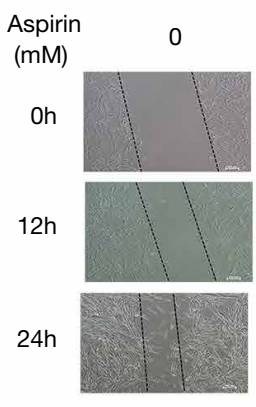

C
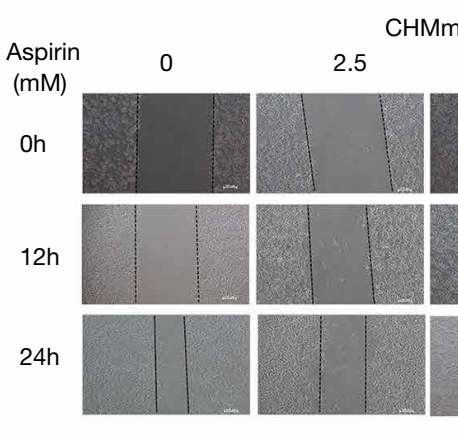

CHMp 5
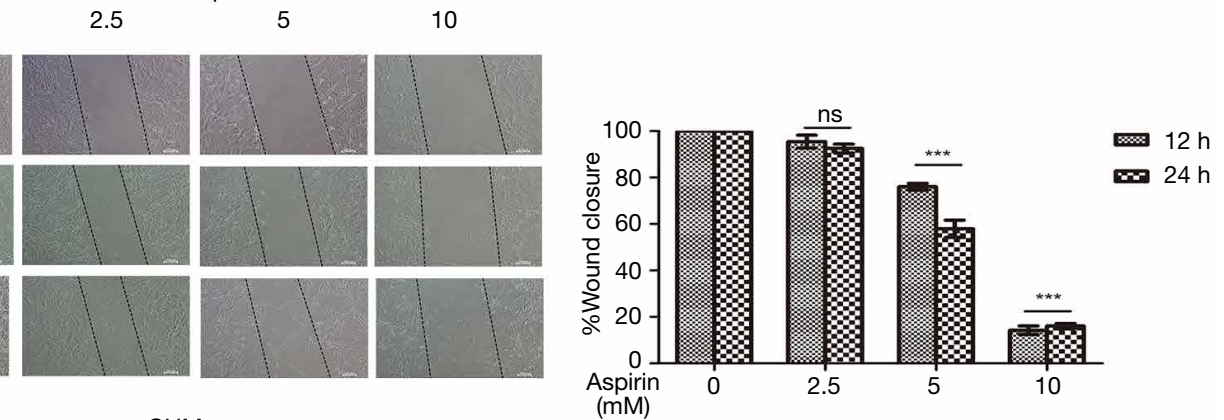

D

0

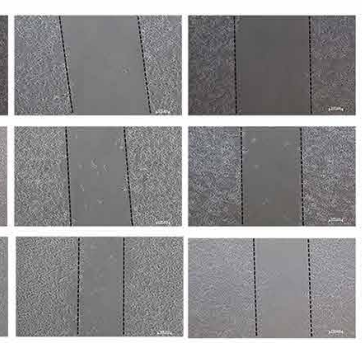

10
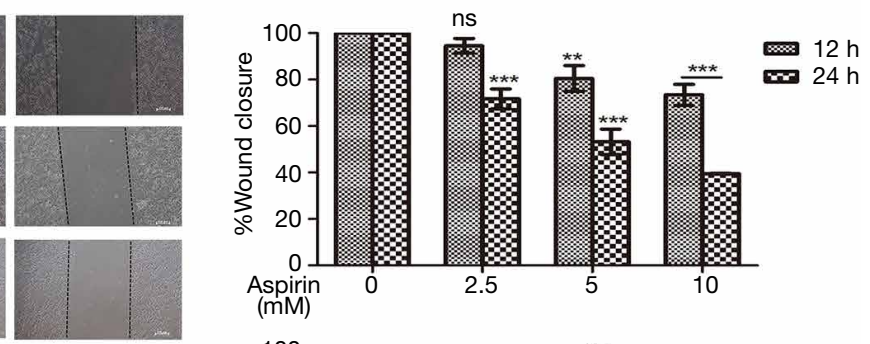

$\mathrm{CHMp}$
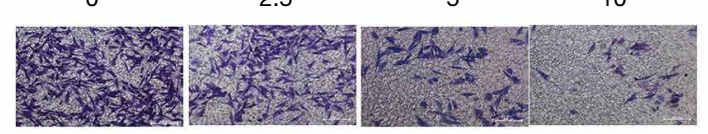

E
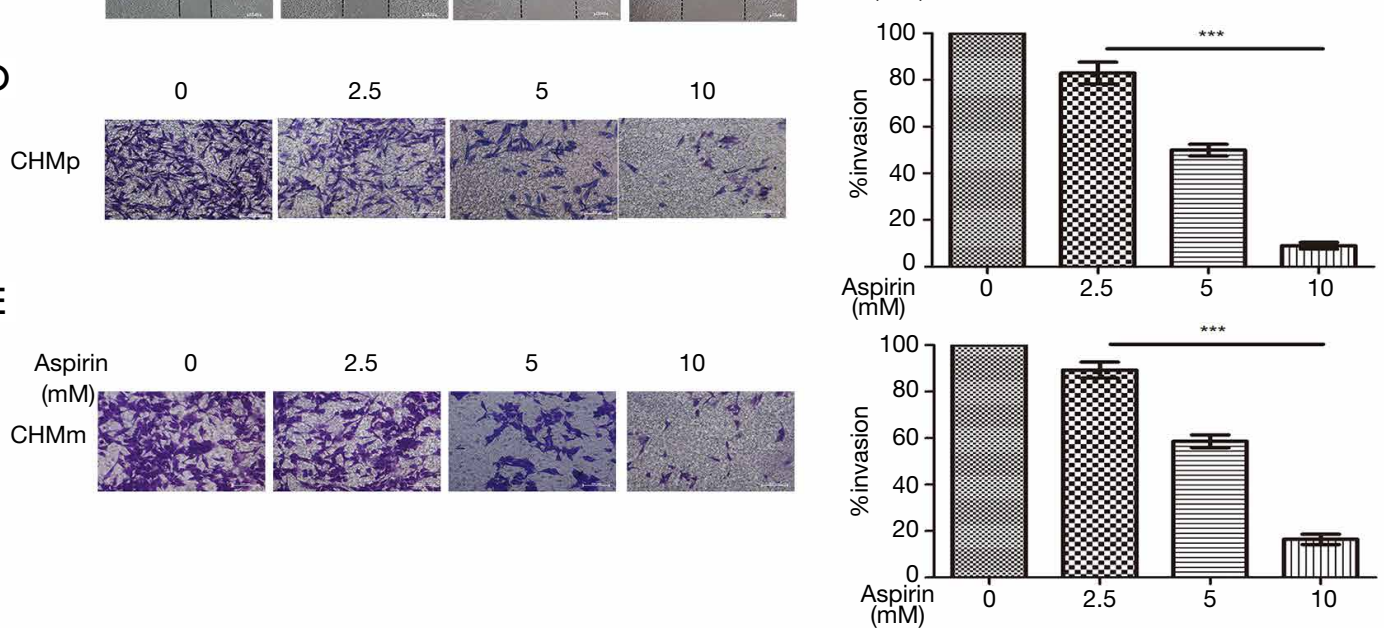

Figure 1 Aspirin inhibits cell proliferation, migration, and invasion using different concentrations on CMGTs. (A) Cytotoxicity of Aspirin treatment on CHMp and CHMm cells after 12 to $72 \mathrm{~h}$ determined using CCK8 assay. Figures are presented as mean \pm SD of six replicates from one of three independent experiments with similar results. (B,C) Wound healing assays were performed in CHMp (B) and CHMm (C) cells treated with $2.5,5$ and $10 \mathrm{mM}$ aspirin. Images of wound closure were captured at 0,12 and $24 \mathrm{~h}$ after treatment. Results were expressed as percent wound closure compared to control. (D,E) Transwell invasion assay was performed in CHMp (D) and CHMm (E) cells treated with $2.5,5$ and $10 \mathrm{mM}$ of aspirin for $36 \mathrm{~h}$ that were seeded ( $0.1 \%$ crystal violet staining, magnification, 200x). Data were expressed as percent invasion in treatment groups compared to controls. Results were expressed as mean \pm SD of three independent experiments $(n=3)$. **, $\mathrm{P}<0.01 ;{ }^{* * *}, \mathrm{P}<0.001$ when compared to untreated group. 
role in the development of cancer. Therefore, we examined whether this pathway was involved in aspirin-induced metastasis in CMGTs. Changes in expression of Wnt/ $\beta$-catenin signaling-related proteins and metastasis-related proteins in CMGTs treated with different concentrations of Aspirin for $36 \mathrm{~h}$ were observed through Western blot analysis. Our results indicated that the expression of Wnt $3 \mathrm{a}$, MMP-2, MMP-9, p-GSK-3 $\beta, \beta$-catenin, PPAR- $\delta$, c-myc and cyclinD1 decreased in a time- and dose-dependent manner (Figure 2) when CMGTs were treated with high concentrations of aspirin $(2.5,5$, or $10 \mathrm{mM})$ and results were more pronounced at the $5 \mathrm{mM}$ dose. Additionally, E-cadherin protein was up regulated. These results indicate that Aspirin inhibits migration and invasion of tumor cells via the $W n t / \beta$-catenin signaling pathway, as well as the protein expression of downstream regulatory molecules in CMGTs.

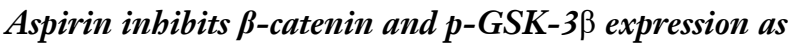 well as nuclear localization in CMGTs}

In order to determine the role of p-GSK-3 $\beta$, and $\beta$-catenin behind the anti-metastatic activity of Aspirin, we examined levels of p-GSK-3 $\beta, \beta$-catenin expression as well as nuclear translocation through confocal immunofluorescence imaging in CMGTs. The p-GSK- $3 \beta$ and $\beta$-catenin protein were engineered to express red fluorescence. Under fluorescent microscope, $\mathrm{p}-\mathrm{GSK}-3 \beta$ protein was mainly expressed in the cytoplasm of CMGTs, while $\beta$-catenin protein was expressed within the cytoplasm and nucleus of CMGTs at the same time. These results (Figure 3) indicated that compared to the control group, the fluorescence intensity of p-GSK-3 $\beta$ and $\beta$-catenin protein in the cytoplasm of CMGTs decreased significantly after treatment with $5 \mathrm{mM}$ aspirin for $36 \mathrm{~h}$, which indicated that aspirin can decrease protein levels of p-GSK-3 $\beta$ and $\beta$-catenin in the cytoplasm of CMGTs, which inhibits the metastasis of $\beta$-catenin to the nucleus as well as metastasis of CMGTs.

\section{The activation of Wnt//-catenin signaling slows down the inbibition of Aspirin on the migration and invasion ability of CMGTs}

Wnt pathway activators (Wnt3a) was added to investigate whether the $\mathrm{Wnt} / \beta$-catenin signaling is associated with invasion and metastasis of CMGTs, prior to the addition of Aspirin. Compared to the control group, the wound healing area of the CMGTs increased with addition of the activator-Wnt3a (Figure $4 A, B, C$ ), while the number of cells invasive cells increased (Figure 4D,E,F). These results show that Wnt3a can slow down inhibition of Aspirin on migration. In addition, we explored the changes in protein following addition of Wnt3a in CMGTs through Western blot analysis. These results indicate that after $\mathrm{Wnt} 3$ a was added, the expression of MMP-2, MMP-9, $\beta$-catenin and CyclinD1 increased, while E-cadherin decreased (Figure $4 G, H, I$ ), which suggests that $\mathrm{Wnt} / \beta$-catenin signaling activation and aspirin-induced inhibition of its migration were alleviated.

\section{The inbibition of the Wnt/ק-catenin signaling inbibits the migration and invasion of CMGTs}

We added the pathway inhibitor FH535 to further explore the role of the $W n t / \beta$-catenin signaling in CMGTs. First, we investigated the effect of FH535 migration and invasion through Wound healing and Transwell invasion assays. The results indicated that $\mathrm{FH} 535$ can inhibit cell migration and invasion (Figure $5 A, B$ ). However, the combination did not produce a drug stack effect compared to using FH535 and Aspirin alone. This was also confirmed by protein results, and the changes of $\mathrm{Wnt} / \beta$-catenin signaling related proteins $\beta$-catenin, p-GSK- $3 \beta$, CyclinD1 and cell metastases related proteins MMP-2, MMP-9 and E-cadherin were not significant (Figure 5C,D). This suggests that Aspirin and FH535 both inhibit the migration and invasion of CMGTs through the Wnt/ $\beta$-catenin signaling.

\section{Discussion}

Tumor metastasis is an important factor for the reduced survival rate of patients. Traditional treatments often have significant side effects. New drug development has always been a hot topic among scholars. NSAIDs have been validated as a treatment for cancer (29). Compared to general chemotherapeutic drugs, aspirin has higher safety and lower toxicity and side effects. In addition, it is a potential anti-tumor drug for chemical prevention and treatment. The protective effect of aspirin on cancer patients has drawn significant attention and exploration. Maity et al. proved that aspirin induces reprogramming factors of EMT in breast tumor cells (30). On the other hand, Khan et al. revealed that Aspirin enhances cisplatin sensitivity of lung carcinoma stem-like cells (11). Additionally, Zhang et al. showed that aspirin is involved in cell migration and Invasion of oral squamous cell carcinoma (31). At the same 
A
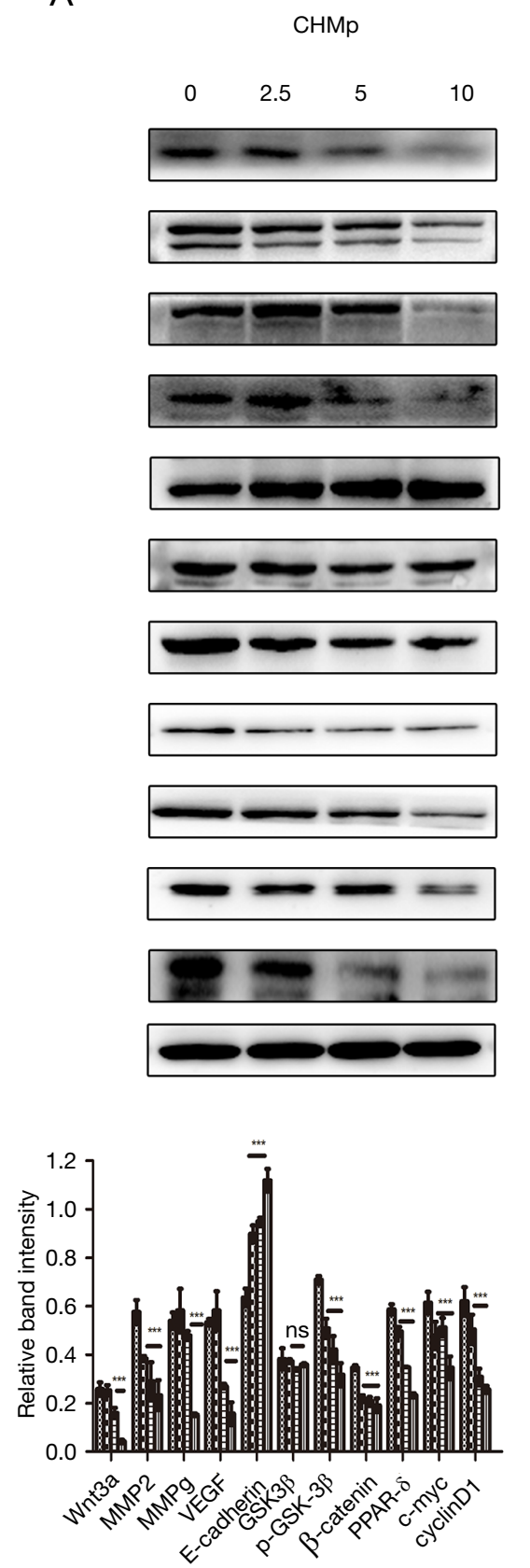

B
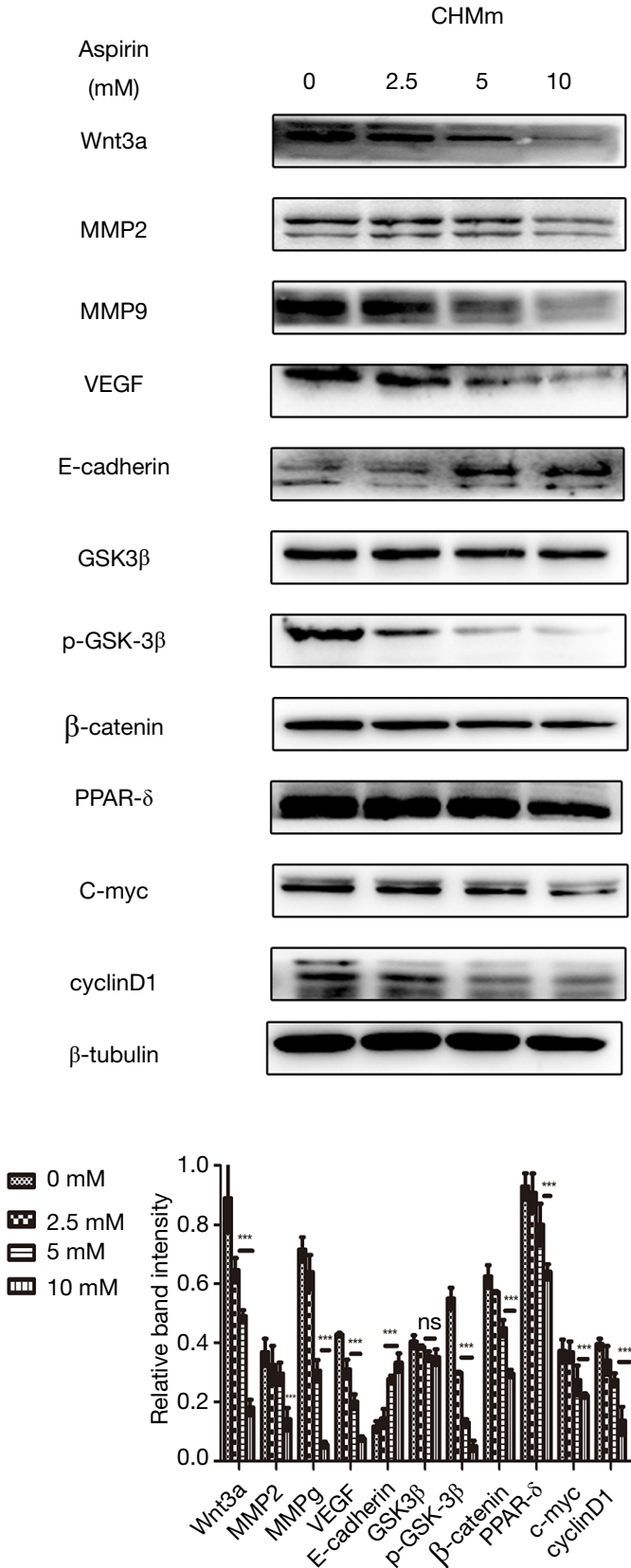

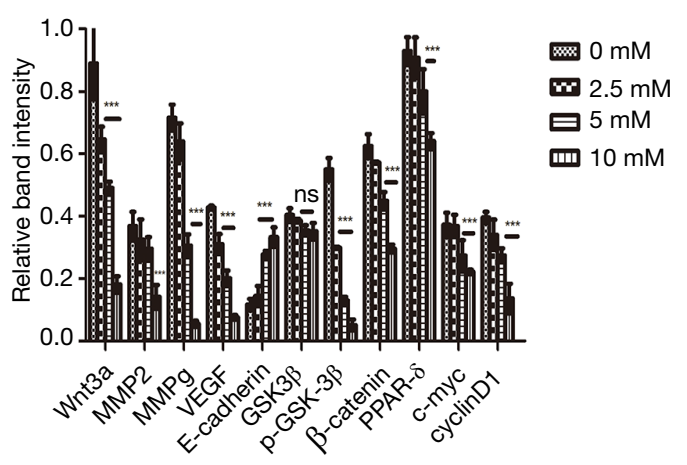

Figure 2 Aspirin inhibits the canonical Wnt/B-catenin pathway in CMGTs. Western blotting showed that Wnt3a, MMP-2, MMP-9, VEGF, p-GSK-3 $\beta$, PPAR- $\delta$ and c-myc were decreased while $\beta$-catenin and E-cadherin were increased in CHMp (A) and CHMm (B) cells treated with high concentrations of aspirin $(2.5,5$, or $10 \mathrm{mM})$. Results were expressed as mean \pm SD of three independent experiments $(\mathrm{n}=3)$. $* * *$ $\mathrm{P}<0.001$ when compared to untreated group. 


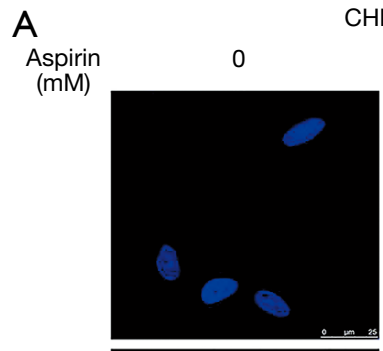

CHMp
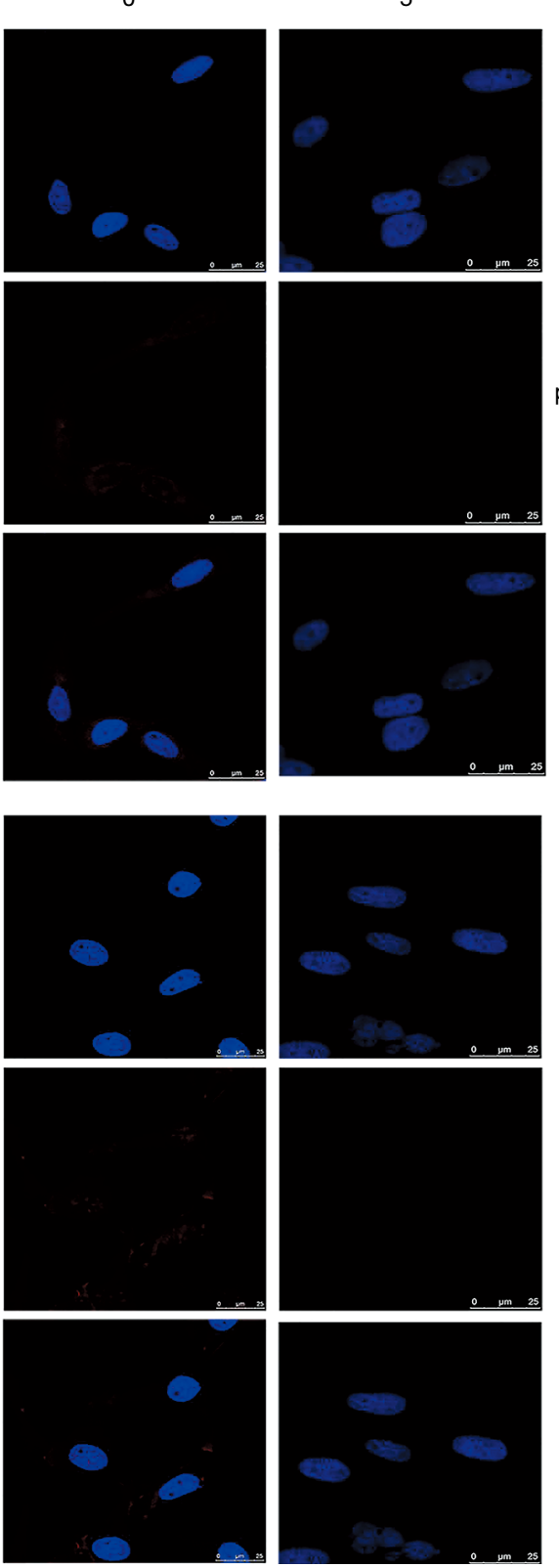

B

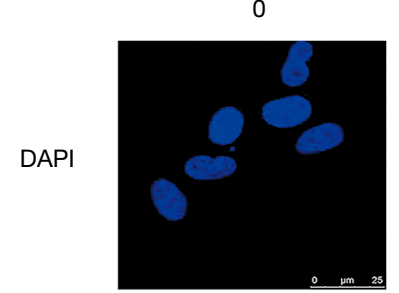

p-GSK-3 $\beta$
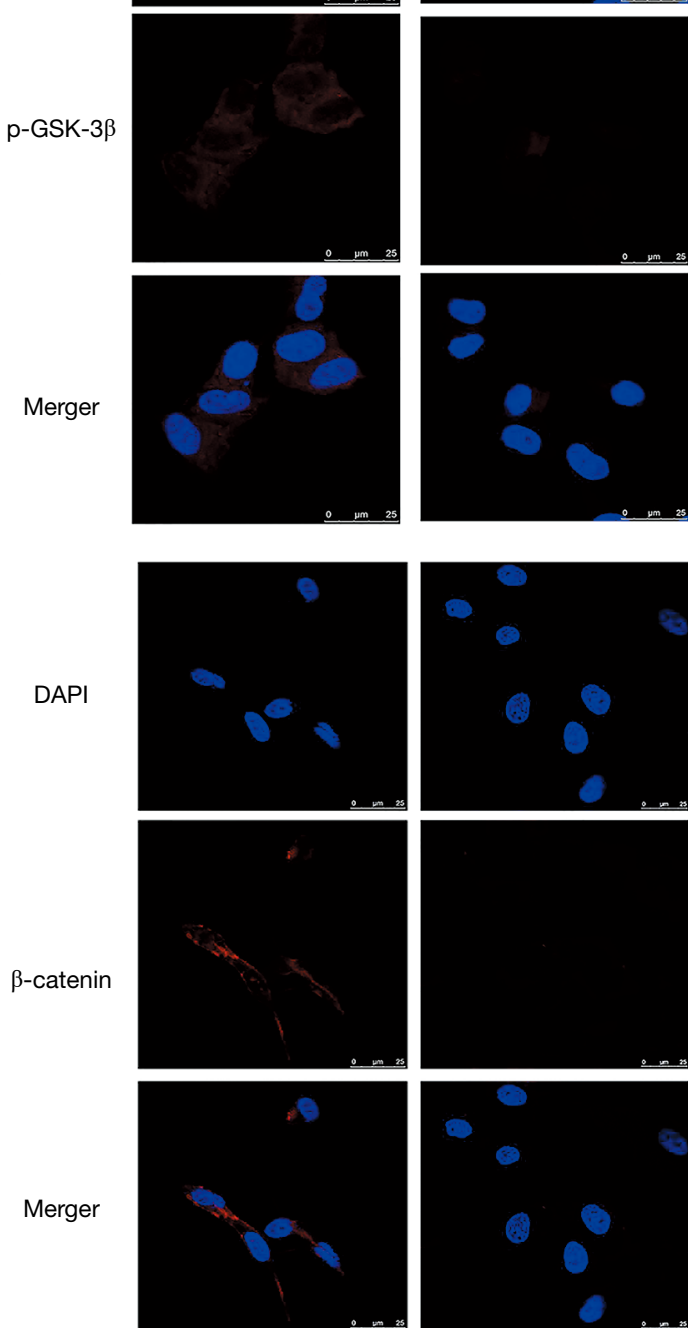
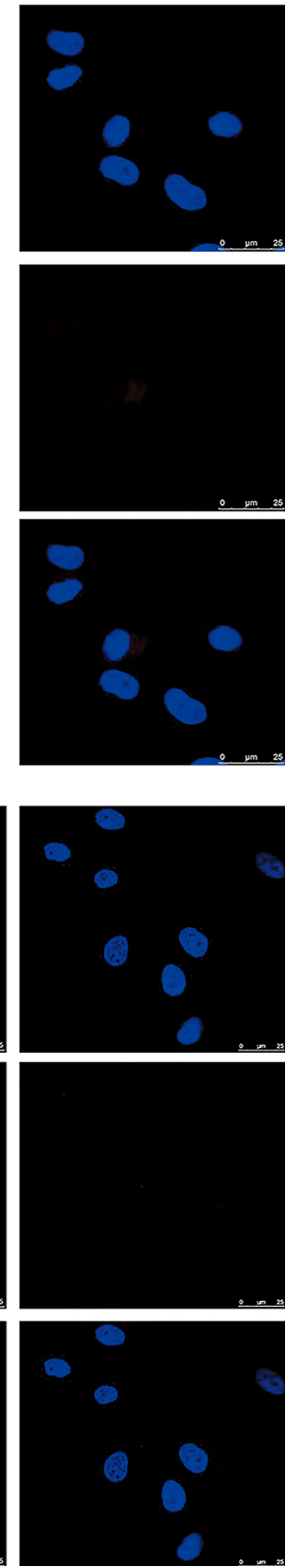

Figure 3 Aspirin inhibited the expression and nuclear translocation of $\beta$-catenin and p-GSK-3 $\beta$ in CMGTs. CHMp (A) and CHMm (B) cells were seeded onto glass for $15 \mathrm{~h}$ and then treated with varying concentrations of Aspirin for $36 \mathrm{~h}$. $\beta$-catenin and p-GSK-3 $\beta$ (red) localization was visualized by immunofluorescence followed by confocal imaging. DAPI was used to stain the nuclear (blue). Images are representative of three-independent experiments. Results were expressed as mean \pm SD of three independent experiments $(n=3)$.

time, there have also been reports of aspirin use in the veterinary oncology field $(15,16)$. However, there have only been a few studies in the field, not just because of the lack of clinical trials date, but also because the development of veterinary medicine has not progressed as rapidly as that of human medicine. Therefore, we first demonstrate that Aspirin is capable of inhibiting proliferation in CMGTs, beginning with the concentrations of $2.5 \mathrm{mM}$ at 12,24 and 
A

$$
\begin{aligned}
& \text { Aspirin } \\
& (\mathrm{mM}) \\
& \text { Wnt3a }
\end{aligned}
$$

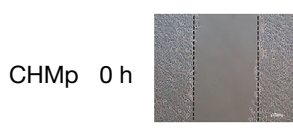

$24 \mathrm{~h}$
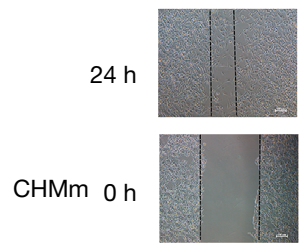

$24 \mathrm{~h}$

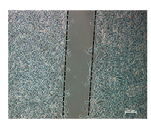

D
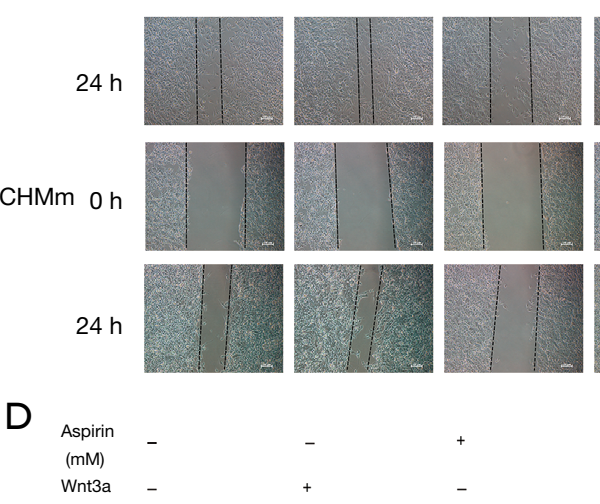

B
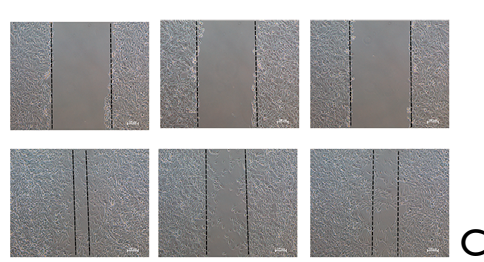

C
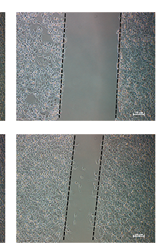

\section{E}

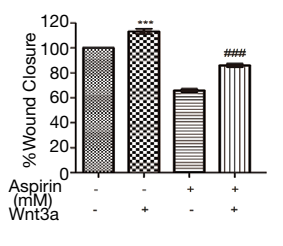

E

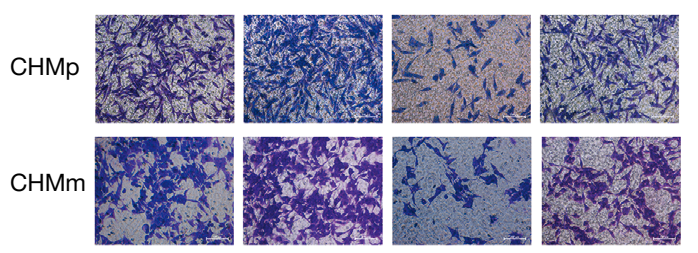

F
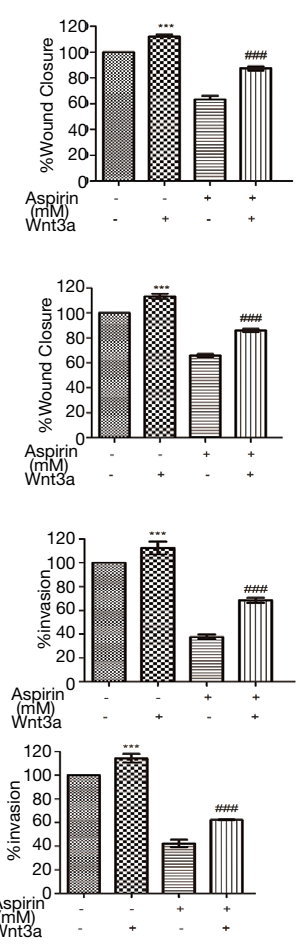

G
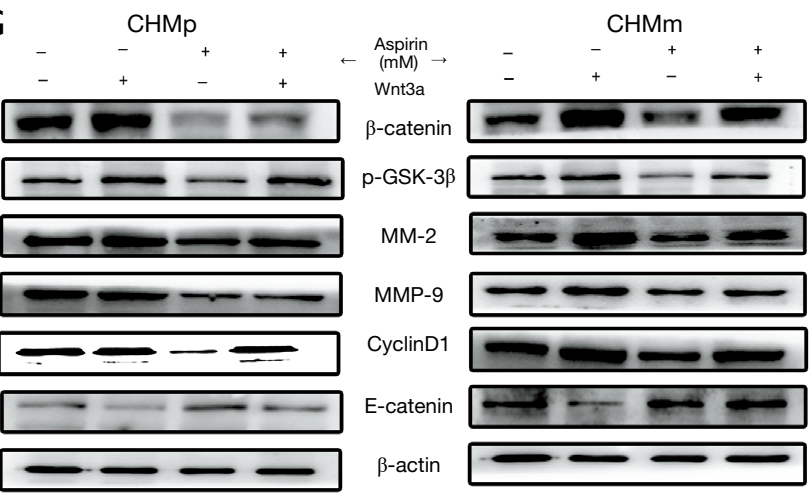

$\mathrm{H}$

I

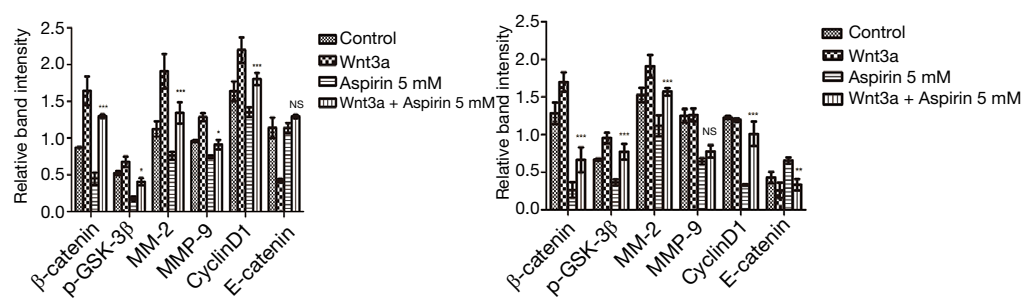

Figure $4 \mathrm{Wnt} 3 \mathrm{a}$ attenuated aspirin-induced inhibition of $\mathrm{Wnt} / \beta$-catenin signaling and migration and invasion of CMGTs. Wound healing (A,B,C) and Transwell invasion assays (B,C,D,E,F) showed that treatment with Wnt3a $(0.1 \mu \mathrm{gg} / \mathrm{mL})$ promoted migration and invasion of CMGTs compared to the untreated group or treatment with only aspirin $(5 \mathrm{mM})(0.1 \%$ crystal violet staining, magnification, 200x). (G,H,I) Wnt3a elevated p-GSK-3 $\beta, \beta$-catenin, MMP-2, MMP-9 and CyclinD1, and it decreased E-cadherin. Results were expressed as mean \pm SD of

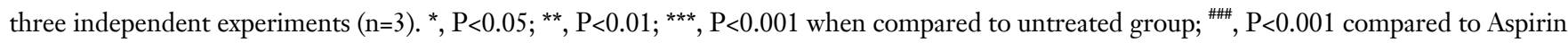
group. 

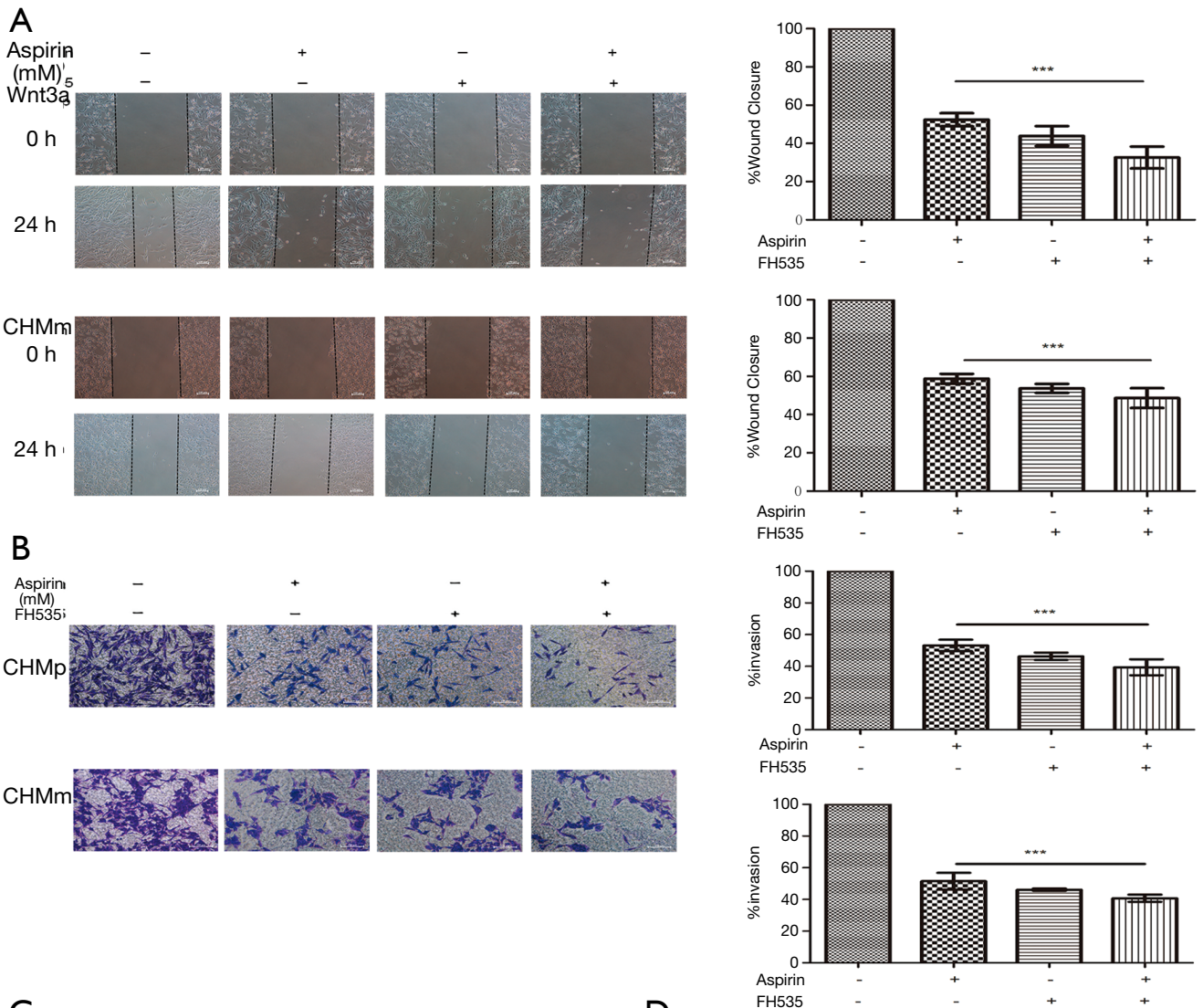

C

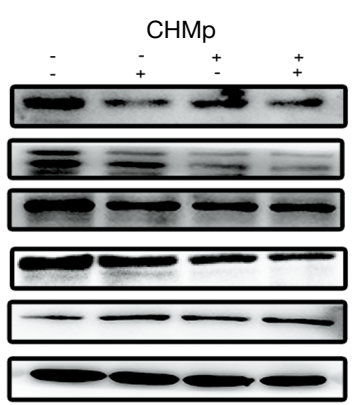

D

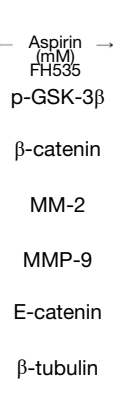
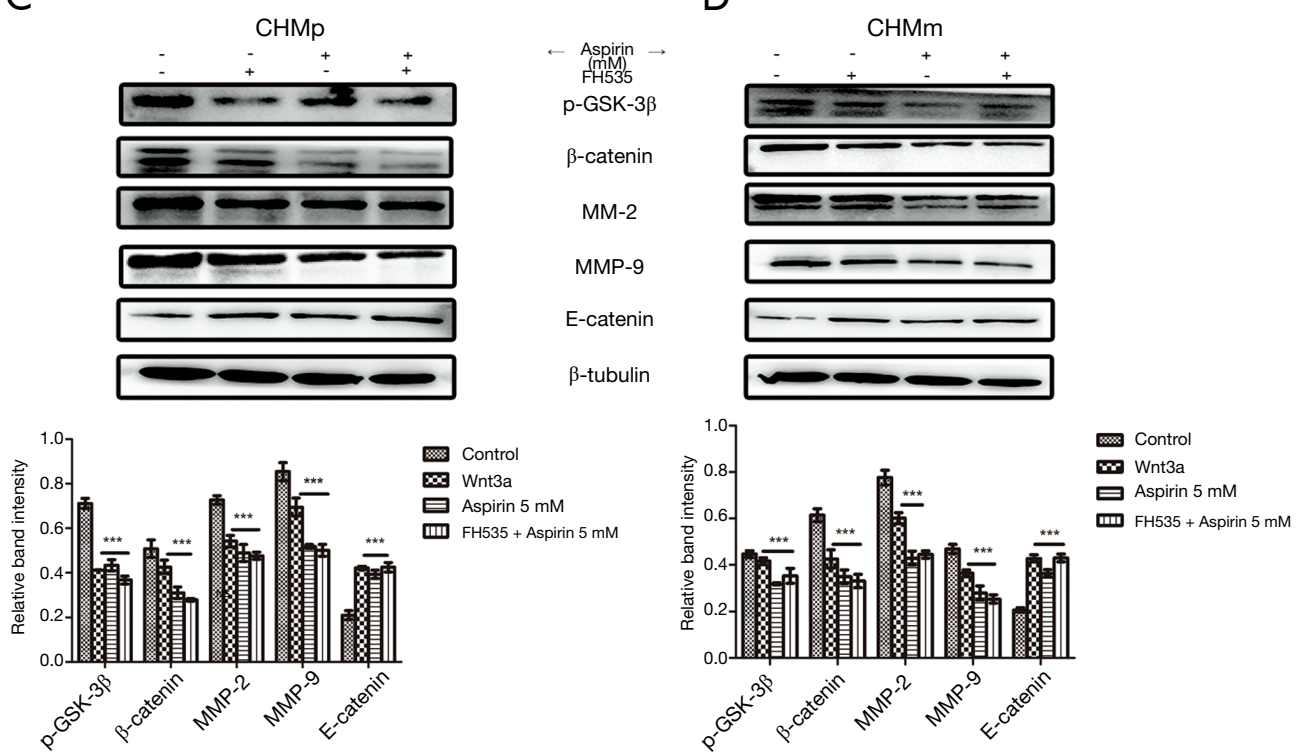

Figure 5 FH535 inhibits cell migration, and invasion in CMGTs. (A,B) Wound healing (A) and Transwell invasion assay (B) showed that treatment with the combination of FH535 and Aspirin inhibited migration and invasion of CMGTs compared with untreated group, but as the same effect of treatment with only aspirin $(5 \mathrm{mM})$ or only FH535 (10 uM) (0.1\% crystal violet staining, magnification, 200x). (C,D) FH535 elevated E-cadherin, and it decreased p-GSK-3 $\beta, \beta$-catenin, MMP-2, MMP-9 and CyclinD1.There was no significant difference between combined drug use and single drug use. Results were expressed as mean \pm SD of three independent experiments ( $n=3)$. ***, $\mathrm{P}<0.001$ when compared to untreated group. 
$36 \mathrm{~h}$, and $1 \mathrm{mM}$ at $48 \mathrm{~h}$, respectively. Results have shown that the antitumor effect is dose-dependent and timedependent. Additionally, Aspirin has the potential of antitumor migration and invasion effect, as demonstrated by the wound healing and transwell invasion assays (Figure 1), which suggests that a high concentration of aspirin can induce CMGTs proliferation and migration.

The antitumor mechanism of aspirin is not well understood. Studies have shown that $\mathrm{Wnt} / \beta$-catenin signaling pathways are downstream of different regulatory molecules, including CyclinD1, and are regarded as aspirin targeting signaling pathways (18). Wnt/ $\beta$-catenin signaling pathway is one of the Wnt signaling pathways that has been studied more thoroughly. The signaling pathway has been shown to regulate the life activities, such as cell proliferation differentiation and apoptosis. Recent studies have indicated that abnormal activation of $\mathrm{Wnt} / \beta$-catenin signaling pathway is closely related to the occurrence and development of tumor cells. Furthermore, mutational inactivation of the $\mathrm{Wnt} / \beta$-catenin signaling pathway inhibitor in the body will accelerates the developmental process of breast cancer, while the up-regulating expression level of DDK-1 as a suppressor gene of the $\mathrm{Wnt} / \beta$-catenin signaling pathway inhibits the formation of breast cancer (32). Andrey et al. showed that in human breast cancer patients, the $\mathrm{Wnt} / \beta$-catenin signaling is highly activated, suggesting poor prognosis in patients with activated $\mathrm{Wnt} / \beta$-catenin signaling (12). A study has also shown that the $\mathrm{Wnt} / \beta$-catenin signaling is also highly active in CMGTs (33).

Here, we tested the effect of aspirin on $W n t / \beta$-catenin signaling-related proteins in CMGTs via western blot analysis. The results indicated that aspirin can reduce expression of p-GSK-3 $\beta$ and $\beta$-catenin proteins (Figure 2). Literature indicates that the maintenance of GSK3 $\beta$ phosphorylation status inhibits its activity. Furthermore, if its phosphorylation level reduces its protein functional activation, this leads to an increase in $\beta$-catenin protein phosphorylation level. Finally, phosphorylated $\beta$-catenin protein will eventually get degraded by ubiquitination, reducing its entry into the nucleus. This will cause the protein levels of downstream targeting regulatory molecules, including $c-m y c$, PPAR- $\delta$, and cyclinD 1 , to decrease. Western blot experiments have shown that aspirin inhibited $\beta$-catenin, c-myc, PPAR- $\delta, M M P-2$, and MMP-9 protein levels in CMGTs, while increasing E-cadherin expression, thereby inhibiting CMGTs migration and invasion. It is worth noting that we did not measure E-cadherin protein level in CHMp cells. We confirmed that Aspirin inhibited the migration and invasion of primary and highly metastatic CMGTs by inhibiting $W n t / \beta$-catenin signaling in a subtoxic concentration range. Our results (Figure 2) from this study are similar to those found in prior research $(11,18,21)$.

In order to further confirm the reliability of these results, we utilized cell immunofluorescence experiments to show that the intracellular signaling of $\mathrm{p}-\mathrm{GSK}-3 \beta$ and $\beta$-catenin. These results (Figure 3) are consistent with previous Western blot experiments. In summary, our experimental results indicate that aspirin can inhibit Wnt/ $\beta$-catenin signaling by inhibiting the phosphorylation of GSK3 $\beta$ protein. However, this is not completely consistent with previous reports. Another study has shown that aspirin does not affect the phosphorylation level of p-GSK3 $\beta$, but instead inhibits the activity of protein phosphatase $2 \mathrm{~A}$ (PP2A), which increases $\beta$-catenin protein as it is degraded through phosphorylation (34). This also indicates that aspirin can affect the phosphorylation level of $\beta$-catenin protein through various pathways, leading to inhibition of $\mathrm{Wnt} / \beta$-catenin signaling.

Cai et al. show that activation of Wnt/ $\beta$-catenin signals enhance the metastatic ability of breast cancer cells and suggested that it can used as a target for drugs to inhibit breast cancer metastasis (35). Therefore, we used the Wnt/ $\beta$-catenin signaling path activator Wnt3a. Our results showed that $\mathrm{Wnt} 3 \mathrm{a}$ alleviated aspirin-induced inhibition of cell migration and invasion (Figure $4 A, B, C, D, E, F$ ). Moreover we found that addition of the Wnt3a activator led of a decrease in MMP-2 and MMP-9, as well as an increase in E-cadherin levels (Figure 4G,I). Our results also suggest the activation of Wnt pathway reversed the inhibitory effect of Aspirin on CMGTs.

Finally, we used the $\mathrm{Wnt} / \beta$-catenin signaling inhibitor (FH535) to inhibit migration and invasion of the CMGTs, and found that the inhibitory effect was similar to that of Aspirin (Figure $5 A, B$ ). The inhibitor FH535 and Aspirin were used in combination and did not produce a drug overlay effect. This was also confirmed by Western blot analysis. Our results (Figure 5C,D) suggest that the inhibitory effect is similar, and that the same suppression mechanism is present. The $\mathrm{Wnt} / \beta$-catenin signaling does play an important role in proliferation of CMGTs, and inhibition of proliferation and migration of cells can be caused by inhibition of the $\mathrm{Wnt} / \beta$-catenin pathway. However, it must be pointed out that the effect of aspirin in CMGTs is more complex, and likely has an effect on the activity of various signaling paths and molecules within the cell. Furthermore, the regulatory process of tumor 
metastatic movement is also complex. Hence, we speculated that the mechanism of aspirin by which aspirin plays a significant role in inhibiting migration and invasion of CMGTs is not caused by a single factor, and may be due to a result of controlling multiple signaling pathways and molecules within the cells.

This study highlights the potential role of aspirin in inhibiting EMT and MMps. Taken together, our data suggests that aspirin can inhibit tumor metastasis by inhibiting the Wnt signaling pathway. However, we did not verify where Wnt3a was responsible for inhibiting of cellular apoptosis in vivo. We also did not observe the antitumor effect of Aspirin in a CMGT model. Finally, the dose of aspirin used in the human body needs to be determined.

\section{Conclusions}

This study is the first to demonstrate that aspirin is involved in the migration of CMGTs through the $\mathrm{Wnt} / \beta$-catenin pathway. Molecules associated with Wnt signaling may be useful therapeutic targets. It is worth noting that further discussion is needed to determine whether aspirin inhibition outweighs its side effects.

\section{Acknowledgments}

The authors are grateful to Professor N. Sasaki, University of Tokyo for kindly providing the CHMp, CHMm cell lines and thanks to the help of the Veterinary Surgery Laboratory at the College of Veterinary Medicine, Northeast Agricultural University.

Funding: This work was supported by the National Natural Science Foundation of China (Grant No. 31872527 and No. 31672617).

\section{Footnote}

Reporting Checklist: The authors have completed the MDAR checklist. Available at http://dx.doi.org/10.21037/tcr-203172

Data Sharing Statement: available at http://dx.doi. org/10.21037/tcr-20-3172

Conflicts of Interest: All authors have completed the ICMJE uniform disclosure form (available at http://dx.doi. org/10.21037/tcr-20-3172). The authors have no conflicts of interest to declare.
Ethical Statement: The authors are accountable for all aspects of the work in ensuring that questions related to the accuracy or integrity of any part of the work are appropriately investigated and resolved.

Open Access Statement: This is an Open Access article distributed in accordance with the Creative Commons Attribution-NonCommercial-NoDerivs 4.0 International License (CC BY-NC-ND 4.0), which permits the noncommercial replication and distribution of the article with the strict proviso that no changes or edits are made and the original work is properly cited (including links to both the formal publication through the relevant DOI and the license). See: https://creativecommons.org/licenses/by-nc-nd/4.0/.

\section{References}

1. Robert J. Biology of cancer metastasis. Bull Cancer 2013;100:333-42.

2. Singh M, Yelle N, Venugopal C, et al. EMT: Mechanisms and therapeutic implications. Pharmacol Ther 2018;182:80-94.

3. Ci Y, Zhang Y, Liu Y, et al. Myricetin suppresses breast cancer metastasis through down-regulating the activity of matrix metalloproteinase (MMP)-2/9. Phytother Res 2018;32:1373-81.

4. Yoshida K, Yoshida S, Choisunirachon N, et al. The relationship between clinicopathological features and expression of epithelial and mesenchymal markers in spontaneous canine mammary gland tumors. J Vet Med Sci 2014;76:1321-7.

5. Fingleton B. Matrix metalloproteinases: roles in cancer and metastasis. Front Biosci 2006;11:479-91.

6. Liu B, Cui J, Sun J, et al. Immunolocalization of MMP9 and MMP2 in osteolytic metastasis originating from MDA-MB-231 human breast cancer cells. Mol Med Rep 2016;14:1099-106.

7. Prescott LF. Paracetamol: past, present, and future. Am J Ther 2000;7:143-7.

8. Sandler RS, Halabi S, Baron JA, et al. A randomized trial of aspirin to prevent colorectal adenomas in patients with previous colorectal cancer. N Engl J Med 2003;348:883-90.

9. Bagheri M, Tabatabae Far MA, Mirzaei H, et al. Evaluation of antitumor effects of aspirin and LGK974 drugs on cellular signaling pathways, cell cycle and apoptosis in colorectal cancer cell lines compared to oxaliplatin drug. Fundam Clin Pharmacol 2020;34:51-64. 
10. Rosenberg K, Mechcatie E. Low-Dose Aspirin Use Associated with Lower Ovarian Cancer Risk. Am J Nurs 2019;119:50.

11. Khan P, Bhattacharya A, Sengupta D, et al. Aspirin enhances cisplatin sensitivity of resistant non-small cell lung carcinoma stem-like cells by targeting mTOR-Akt axis to repress migration. Sci Rep 2019;9:16913.

12. Khan FU, Owusu-Tieku NYG, Dai X, et al. Wnt/betaCatenin Pathway-Regulated Fibromodulin Expression Is Crucial for Breast Cancer Metastasis and Inhibited by Aspirin. Front Pharmacol 2019;10:1308.

13. Liao D, Zhong L, Duan T, et al. Aspirin Suppresses the Growth and Metastasis of Osteosarcoma through the NFkappaB Pathway. Clin Cancer Res 2015;21:5349-59.

14. Li Y, Brasky TM, Nie J, et al. Use of nonsteroidal anti-inflammatory drugs and survival following breast cancer diagnosis. Cancer Epidemiol Biomarkers Prev 2012;21:239-42.

15. Knapp DW, Chan TC, Kuczek T, et al. Evaluation of in vitro cytotoxicity of nonsteroidal anti-inflammatory drugs against canine tumor cells. Am J Vet Res 1995;56:801-5.

16. Saito T, Tamura D, Asano R. Usefulness of selective COX2 inhibitors as therapeutic agents against canine mammary tumors. Oncol Rep 2014;31:1637-44.

17. Neth P, Ries C, Karow M, et al. The Wnt signal transduction pathway in stem cells and cancer cells: influence on cellular invasion. Stem Cell Rev 2007;3:18-29.

18. Gala MK, Chan AT. Molecular pathways: aspirin and Wnt signaling-a molecularly targeted approach to cancer prevention and treatment. Clin Cancer Res 2015;21:1543-8.

19. Huang N, Chen D, Wu X, et al. Aspirin Promotes Oligodendroglial Differentiation Through Inhibition of Wnt Signaling Pathway. Mol Neurobiol 2016;53:3258-66.

20. Wang Y, Tang H, He G, et al. High Concentration of Aspirin Induces Apoptosis in Rat Tendon Stem Cells via Inhibition of the Wnt/beta-Catenin Pathway. Cell Physiol Biochem 2018;50:2046-59.

21. Sorenmo K. Canine mammary gland tumors. Vet Clin North Am Small Anim Pract 2003;33:573-96.

22. Sun J, Guo C, Zheng W, et al. Aspirin inhibits proliferation and promotes apoptosis of hepatocellular carcinoma cells via wnt/beta-catenin signaling pathway. Panminerva Med 2020. [Epub ahead of print]. doi: 10.23736/S0031-0808.19.03722-4.

23. Yang C, Liu J, Wang YX, et al. Aspirin inhibits the proliferation of canine mammary gland tumor cells in vitro and in vivo. Transl Cancer Res 2017;6:188-97.

24. Uyama R, Nakagawa T, Hong SH, et al. Establishment of four pairs of canine mammary tumour cell lines derived from primary and metastatic origin and their E-cadherin expression. Vet Comp Oncol 2006;4:104-13.

25. Hseu YC, Chang GR, Pan JY, et al. Antrodia camphorata inhibits epithelial-to-mesenchymal transition by targeting multiple pathways in triple-negative breast cancers. J Cell Physiol 2019;234:4125-39.

26. Shukla S, Sinha S, Khan S, et al. Cucurbitacin B inhibits the stemness and metastatic abilities of NSCLC via downregulation of canonical Wnt/beta-catenin signaling axis. Sci Rep 2016;6:21860.

27. Peng B, He R, Xu Q, et al. Ginsenoside 20(S)protopanaxadiol inhibits triple-negative breast cancer metastasis in vivo by targeting EGFR-mediated MAPK pathway. Pharmacol Res 2019;142:1-13.

28. Tieng FYF, Latifah SY, Md Hashim NF, et al. Ampelopsin E Reduces the Invasiveness of the Triple Negative Breast Cancer Cell Line, MDA-MB-231. Molecules 2019;24:2619.

29. Crusz SM, Balkwill FR. Inflammation and cancer: advances and new agents. Nat Rev Clin Oncol 2015;12:584-96.

30. Maity G, De A, Das A, et al. Aspirin blocks growth of breast tumor cells and tumor-initiating cells and induces reprogramming factors of mesenchymal to epithelial transition. Lab Invest 2015;95:702-17.

31. Zhang X, Feng H, Li Z, et al. Aspirin is Involved in the Cell Cycle Arrest, Apoptosis, Cell Migration, and Invasion of Oral Squamous Cell Carcinoma. Int J Mol Sci 2018;19:2029.

32. Mukherjee N, Bhattacharya N, Alam N, et al. Subtypespecific alterations of the Wnt signaling pathway in breast cancer: clinical and prognostic significance. Cancer Sci 2012;103:210-20.

33. Uva P, Aurisicchio L, Watters J, et al. Comparative expression pathway analysis of human and canine mammary tumors. BMC Genomics 2009;10:135.

34. Bos CL, Kodach LL, van den Brink GR, et al. Effect of aspirin on the $\mathrm{Wnt} /$ beta-catenin pathway is mediated via protein phosphatase 2A. Oncogene 2006;25:6447-56.

35. Cai J, Guan H, Fang L, et al. MicroRNA-374a activates Wnt/beta-catenin signaling to promote breast cancer metastasis. J Clin Invest 2013;123:566-79.

Cite this article as: $\mathrm{Xu} \mathrm{E}, \mathrm{Hu} \mathrm{M}$, Liu Y. Aspirin inhibits proliferation and metastasis of canine mammary gland tumor cells through Wnt signaling axis. Transl Cancer Res 2021;10(2):589-601. doi: 10.21037/tcr-20-3172 